\title{
Homem, Realidade, Interpretação
}

O texto fala da constituição de realidade enquanto e como interpretação. Por interpretação é entendida a ação, a atividade de (um) sentido, que sempre já aconteceu, se deu ou se interpôs. Sentido, i.é, lógos, i.é, mundo, que ainda se revela e se articula como interesse e/ou perspectiva. Desde salto (subitaneidade, i-mediatidade) esta ação é ex-posição, auto-ex-posição de sentido (lógos, mundo, interesse, perspectiva), ou seja, movimento, atividade desde ou a partir de si mesma e que move a si mesma (= vida, psyché). Salto, súbito, define igualmente círculo, i.é, inserção, e então, afeto (páthos). Tudo isso constitui uma estrutura, melhor, uma composição, ou seja, trata-se de um único e mesmo instante, acontecimento ou ato. Portanto, nada ordenado e sequenciado segundo, p.ex., fundamento e $(+)$ fundado, anterior e $(+)$ posterior, causa e $(+)$ efeito. Não. Um só ato - súbito, a-byssal.

realidade, interpretação, (ação, atividade de) sentido

PALAVRAS-CHAVE (lógos, mundo, interesse, perspectiva), salto, circularidade, inserção, afeto.

Der Text beschreibt Realitätsverfassung als Interpretation. Interpretation wird als die Tätigkeit eines Sinnes verstanden, der sich immer erst hineingelegt worden ist. Sinn sagt lógos (Welt), den sich noch als Interesse und/oder Perspektive zeigt. Aus Sprung (Plötzlichkeit, Un-mittelbarkeit) heraus verstanden, ist diese Tätigkeit Sinnesaussetzung (Ex-position), d.h., eine sich von sich selbst Bewegung/Tätigkeit (= Leben, Psyché). Sprung (Plötzlichkeit, Unmittelbarkeit) zeichnet sich zugleich als Kreis und Affekt (Páthos) aus. Alles dies bestimmt sich als ein Gefüge (eine Struktur, ein Gestell) es geht denn um einen und einzigen Augenblick oder eine und einzige Tat — plötzlich, ab-gründig. 
Homem, Realidade, Interpretação $\quad$ Prof. Dr. Gilvan Fogel

\section{Você tinha razão, você tinha razão. Era no círculo que precisava ser procurado. Era no círculo que...}

1. Afixado à porta de uma loja especializada em artigos, em artesanato de pedra, lê-se:

\section{A Pedra}

O distraído nela tropeçou.

O bruto a usou como projétil

O empreendedor, usando-a, construiu.

O camponês, cansado da lida, dela fez assento.

Para meninos, foi brinquedo.

Drummond a poetizou.

Já David matou Golias e Miguelangelo extraiu-lhe a mais bela escultura.

Em todos estes casos, a diferença não esteve na pedra, mas no homem!

O texto ainda continua, mas nós, atônitos, cofiando - não, hoje ninguém mais cofia a barba! - coçando a barba, paramos, ponderamos e perguntamos: afinal, o que é a pedra? Em cada caso, em cada situação mencionada, tem-se, a cada vez, uma outra pedra. Seria, como o hermeneuta da boutique insinua, a pedra sempre a mesma pedra e o que, a cada vez, muda, mudou, seria o homem? Seria, então, o homem a causa, o autor, o criador da pedra, a cada vez? Então, a pergunta não seria "O que é a pedra?", mas, antes, "O que — ou, melhor ainda, quem é o homem?"

O que parece, de início, é que pedra, a cada vez, é ou dá-se em uma relação - a relação homem-pedra. Relação ou perspectiva. Ou, ainda, interesse. E, de cara, tudo indica, perspectiva, interesse, ponto de vista - tudo isso é coisa de, do homem, isto é, coisa da vontade, da subjetividade humana. Pedra, assim, a cada vez, seria, sim, obra, resultado, conseqüência ou produto da vontade, da subjetividade humana. Enfim, do homem, pura e simplesmente. 
Homem, Realidade, Interpretação $\mid$ Prof. Dr. Gilvan Fogel

No texto citado, ficou insinuado que pedra é, foi, seria sempre a mesma pedra e o que muda, mudou e mudaria sempre é o homem, talvez sua idiossincrasia ou seu capricho, a sua vontade ou, melhor, digamos, sua perspectiva, seu interesse ou ainda seu ponto de vista. Sempre a mesma pedra?! Qual mesma? Como? Seria esta, talvez, a pedra em si? E qual seria, onde seria a pedra em si, objetiva, esta pedra sempre a mesma, ou seja, a substância pedra propriamente dita? Seria, por exemplo — quem sabe! — , a pedra do geólogo? Ou a do químico?! Esta seria, talvez, a pedra verdadeira, a pedra em si, a pedra da objetividade científica - pesada, medida, verificada. Ou geólogo e químico (a ciência), cada qual, seria, mais uma vez, tão-só uma outra pedra possível?

Vamos parar por aqui para começar a andar com essa pedra no meio do nosso caminho, que já virou pedra no sapato e que começa a incomodar. Parar para andar - isso é paradoxal. Mas este parar é, precisará ser o andar da pergunta, do perguntar. Vamos, pois, parar, perguntar e, assim e por isso, andar. A este tipo de andar instiga sempre a comichão da pergunta - a pedra no sapato-filosofia.

2. A pedra em si, tudo indica, não há, não pode haver. A pedra em si seria a pedra independente, fora de toda e qualquer relação. Mas relação é a condição necessária, absolutamente necessária para que pedra, isto é, toda e qualquer coisa, seja pedra - quer dizer, para que toda e qualquer coisa seja a coisa que é e tal como é, ou seja, tal como aparece e se mostra sendo.

Ao invés de falarmos relação, pode-se dizer que pedra sempre é ou torna-se pedra, esta pedra, em uma ou, melhor, a partir de uma dimensão; em um ou a partir de um horizonte. Dimensão está falando de uma abertura, de um âmbito. Um âmbito que constitui uma medida, que dá uma medida. Justo esta medida, ou seja, o âmbito ou mesmo a delimitação, é o horizonte.

Cercando e procurando melhor caracterizar esta relação, que se mostra como dimensão e horizonte, âmbito e medida, vê-se que tal medida ou âmbito, na verdade, de fato, se realiza ou se concretiza como um interesse, como uma perspectiva. Talvez, como habitualmente se diz, um ponto de vista.

Dito isso, a observação, a objeção que imediatamente se faz é esta: bem, se assim é, então, pedra, toda pedra, quer dizer, toda e qualquer coisa, é sempre algo subjetivo, pois interesse, perspectiva ou ponto de vista é sempre coisa subjetiva, obra ou produto da subjetividade, da vontade humana. 
Homem, Realidade, Interpretação $\mid$ Prof. Dr. Gilvan Fogel

3. Foi dito: o empreendedor, isto é, o empreiteiro, o pedreiro, vendo a pedra, dela se apropriou, quer dizer, trouxe-a para junto de seu próprio, seu ser-pedreiro - enfim, assim vendo a pedra, construiu; a criança, vendo a mesma (?!) pedra desde o seu próprio, o mundo-jogo-criança, dela assim se apropriou e brincou, ou seja, a pedra virou mundo de jogo; Drummond a poetizou, quer dizer, pedra agora foi vista e apropriada no ou desde o mundo, o interesse ou a perspectiva poesia; Miguelangelo esculpiu, ou seja, apropriou-se de pedra, da mesma (!?) pedra, desde o mundo, a dimensão ou o horizonte escultura.

No caso, a cada vez, construção (arquitetura, fazer moradia), jogo, mundo-jogo, poesia, escultura são as dimensões, os horizontes ou, como também dissemos, os interesses, as perspectivas ou os pontos de vista desde os quais, a partir dos quais, a cada vez, pedra é pedra. Vimos e dissemos ainda: pedra só é pedra, só pode ser pedra em um, desde ou a partir de um horizonte (i.é, dimensão, perspectiva, interesse), pois não há, não pode haver pedra em si, destituída ou fora de toda e qualquer relação, destituída ou fora de todo e qualquer interesse, ou perspectiva, ou ponto de vista. Imaginar ou querer a pedra em si, seria imaginar ou querer pedra, toda e qualquer coisa, destituída ou fora da condição absolutamente necessária para que pedra possa ser pedra, para que o quê quer que seja, seja isso que é, tal qual é, aparece ou se mostra. E imaginar, desejar, aspirar ou querer o impossível, isto é, o que absolutamente está fora de toda e qualquer condição de possibilidade de ser - isso já é o domínio da presunção, da sanha, da hybris.

4. Agora, a pergunta é: construção (arquitetura), jogo, poesia, escultura — as dimensões, os interesses, as perspectivas (pontos de vista) ou relações possíveis — isso tudo é coisa, quer dizer, é produto, é resultado, conseqüência ou obra do homem? Tais dimensões ou horizontes são invenções, criações da subjetividade humana, construções da consciência autônoma ou da vontade livre do homem?!

E se invertermos e perguntarmos: seria, ao contrário, a subjetividade ou a vontade humana, em suma, seria o homem obra, criação de tais aberturas, interesses, perspectivas?! Seria o homem, este homem, cada homem, resultado, invenção (!), a cada vez, de tais dimensões, horizontes?! Assim como pedra (!?), seria também o homem apoderado e apropriado, p.ex., por arquitetura, por jogo, por poesia, por escultura e, então, ele só poderia ser compreendido em uma, desde ou a partir de uma tal relação vital-existencial possível, ou seja, somente desde ou a partir de um tal horizonte, perspectiva ou ponto de vista? 
Homem, Realidade, Interpretação $\mid$ Prof. Dr. Gilvan Fogel

Em sendo assim, então, o sujeito, a causa, o princípio ou a substância, seja do homem, seja da pedra e do que quer que seja, seria a relação, a abertura, isto é, o horizonte, a dimensão, o interesse ou a perspectiva. Então, em assim sendo, o em si, a coisa em si, ficou transferida para a dimensão, o horizonte, o interesse. E, adiando ou protelando mais, o que, quem ou qual é a causa desta causa, isto é, o sujeito ou a causa do interesse, da perspectiva? Seria coisa de Deus, do Espírito Santo?! Coisa do Sobrenatural do Almeida ou algo do Doente imaginário, expediente hipocondríaco de Argan?! Ou ainda coisa gerada no e saída do Cafarnaum, do M. Homais?!

Mas Deus, Espírito Santo, assim como o Sobrenatural do Almeida, na filosofia, é coisa de preguiçoso e, sobretudo, recurso, fantasia de bípede ingrato. De qualquer modo, ficamos na obrigação de esclarecer a natureza, o modo de ser de perspectiva (horizonte, interesse) e igualmente a afirmação, segundo a qual o homem, assim como pedra ou qualquer outra coisa, seja, venha a ser desde e como horizonte, interesse, perspectiva. O que é, como é esta relação, por nós sobrecarregada com as denominações interesse, perspectiva, dimensão, horizonte, ponto de vista, e que é a condição necessária, a conditio sine qua non, de toda e qualquer realidade possível? E, nisso tudo, o que é, como é o homem? E, mais uma vez, a coisa, as coisas, o real, todo e qualquer real possível?

5. Quando uma pedra acontece, i.é, aparece, se dá, como esta ou como aquela pedra, um interesse, uma perspectiva (dimensão, horizonte) sempre já se deu, sempre já aconteceu. "Uma coisa em si é algo tão absurdo quanto um sentido em si, uma significação em si. Não há nenhum fato, nenhum estado de fato em si, pois, para que possa haver um estado de fato, é preciso que, antes, um sentido seja/esteja sempre já introduzido", escreveu Nietzsche ${ }^{1}$. A expressão sempre já, empregada acima (o que, na citação de Nietzsche, corresponde ao "antes... seja sempre" - ein Sinn muss immer erst hineingelegt werden), é chave, é decisiva, pois ela aponta para o caráter de salto ou de i-mediatidade e, então, de prévio, de antecipação (a priori), assim como igualmente de inserção (círculo ou circularidade), da perspectiva ou do interesse fundador, instaurador ou inaugurador de coisa, de algo — qualquer que seja. Esta ou este é o sentido, quer dizer, o lógos, o mundo sempre já irrompido, de modo a tornar possível o que aparece ou se dá, tal como se dá ou aparece. Ou seja, quando se vê algo, vê-se porque (graças a) já se está tomado, atravessado ou perpassado por uma per-spectiva ou por um

1 Cf. Nietzsche, F., A Vontade de Poder, Contraponto, Rio de Janeiro, 2008, nr. 556, pág. 290/1 ou KGW VIII-1, 2[149], p. 138 
Homem, Realidade, Interpretação $\mid$ Prof. Dr. Gilvan Fogel

inter-esse. Tomado, atravessado, perpassado, isto é, em pleno meio, medium ou elemento. Este ser ou estar Este ser ou estar tomado por dá o caráter de inserimento ou de inserção, que é ser sob a forma ou sob o modo de ser dito na imagem de círculo ou de circularidade. Círculo ou circularidade, pois, é a tentativa de dizer, através de uma imagem, uma experiência arcaico-originária, que não tem ou não é imagem alguma, a saber, o próprio fenômeno ("Urphänomen") da vida, da existência humana, enquanto e como inserção e afeto ou páthos. Porque ou graças a salto, súbito ou i-mediato - por isso, graças a isso, dá-se círculo, acontece circularidade; faz-se inserção e, então (!), afeto, páthos. Na verdade, tudo isso é um único e mesmo instante, um único e mesmo ato.

A perspectiva ou o interesse tem ou, melhor, é a forma ou a estrutura do afeto (páthos), uma vez que ela ou ele toma, apodera-se ou apropria-se do homem. E isso à medida que perspectiva ou interesse vem sobre o homem, lhe sobrevém, e assim o toma, dele apoderando-se ou apropriando-se. Quer dizer, apodera-se ou apropria-se do ente, antes e melhor, do modo de ser, que é apoderável ou apropriável, isto é, afetável. E tal modo de ser é o próprio do homem e só do homem, o qual originariamente é nada, ou seja, coisa nenhuma, algo nenhum determinado, mas só e tão-só a possibilidade de ser tocado, tomado ou afetado por uma perspectiva, por um interesse, quer dizer, por uma possibilidade ou um sentido (lógos, mundo) possível. E isso quer ainda dizer: o homem e só o homem é possibilidade de ser tomado (tocado, afetado) por possibilidade.

Uma possibilidade que se apodera ou se apropria do homem se concretiza ou se realiza à medida que se ex-põe. E a exposição, quer dizer, concretização ou realização de tal possibilidade, perfaz história. A história (a substância!), que é o homem, que o homem é. E é preciso que se pense e que se considere que uma tal possibilidade (sentido, mundo, interesse, perspectiva), por ser a encarnação ou a concretização da própria vida, isto é, o modo como vida se realiza ou se concretiza - enfim, tal possibilidade é essencial ou constitutivamente realizar-se, concretizar-se em se expondo. Expondo-se, quer dizer, tal possibilidade é necessariamente movimento ou dinâmica de auto-exposição, pois vida (a vida humana, história) é movimento que, desde si mesmo, move (expõe) a si mesmo. Um automóvel, pois. E, como já dito, assim se faz história, a história (o acontecer, o suceder ou o dar-se de tempo se fazendo tempo, a "Geschichte") que cada homem, que todo homem é. Homem, essencial ou necessariamente, é história e só história ou a ação, a atividade de exposição, de auto-exposição de uma perspectiva ou de um interesse (isso é tempo se fazendo tempo ou vindo a ser tempo), o qual se serve do, o qual usa o ente, melhor, o modo de ser usável, apropriável, a saber, o homem e só o homem. E assim, só assim, o homem vem 
Homem, Realidade, Interpretação $\mid$ Prof. Dr. Gilvan Fogel

a ser ou se faz homem, isto é, acontece ou dá-se como este ou como aquele homem determinado. A substância, o ser do homem é história (tempo) e só história (tempo). Ou seja, o homem é ou tem ser nenhum, substância nenhuma.

6. Uma perspectiva (interesse, sentido, mundo) se apropria do homem e, então, o homem vem a ser homem. E alguém, com razão, pergunta: "Ora, como?! O homem, então, é ou há antes do homem?!" A pergunta seria boa se razão, aqui, pudesse ser medida, critério...! Pois quando a medida ou o critério é o súbito, o salto, então, a razão nunca é ou tem razão...! Mas aceitemos a pergunta, a objeção. E a resposta é: sim e não. Não (i.é, o homem não pré- ou sub-existe ao homem), se se pensa homem sempre já como um algo determinado, como já alguma coisa, p.ex., uma alma, um espírito, uma consciência ou, por outro lado, um corpo, uma energia, um lastro ou um aparato bio-fisiológico, um organismo. Ou seja, originariamente o homem não é nenhum isso ou aquilo, pois toda e qualquer determinação desta índole é tardia, epigonal. Sim (quer dizer, o homem é ou seria antes do homem, isto é, deste homem assim caracterizado ou determinado, tardiamente), se se considera, se se vê que, antes e fora do homem concreto, realizado (p.ex., este eu, ou espírito, ou consciência, ou alma, ou corpo, ou energia, João, Pedro, Maria etc., etc.), o que é e há arcaico-originariamente é só e tão-só possibilidade de e para possibilidade. Pois a vida, a existência humana, em suma, o homem, no seu fundo ou lastro ontológico primeiro, essencial, é "a realidade da liberdade como possibilidade para possibilidade". Ou seja, o homem, a vida ou a existência humana, dá-se ou acontece como a abertura, i.é, a disposição ou a pré-disposição (pura espontaneidade ou liberdade) de ser disposição, pré-disposição ou aptidão (possibilidade) para. E isso, a saber, esta realidade da liberdade, é só e tão-só possibilidade de e para possibilidade.

7. Mas alguém, algum realista encardido, insiste, objeta: "Pois me mostre este homem, esta pura possibilidade para possibilidade! Quero ver! Quero a prova, a constatação, a verificação disso." E o erro seria levar a sério esta objeção/reivindicação e querer respondê-la, segundo a medida da objeção, pois tal exigência/reivindicação é coisa de bom senso, de senso comum, quer dizer, ela não fala no e desde o salto, isto é, ela não vê e não sabe o homem, as coisas, realmente desde e como salto, círculo, circularidade e inserção. De novo, tal objeção/reivindicação é distraída, melhor, decaída, pois ela quer o primeiro

2 Cf. Kierkegaard, S., O Conceito de Angustia, Cap. I, § 5 
Homem, Realidade, Interpretação $\mid$ Prof. Dr. Gilvan Fogel

homem. E o primeiro homem não há, nunca houve. Não haverá. E não por falta ou ineficiência da pesquisa paleontológica em direção ao elo perdido. Essencial ou constitutivamente não há e não pode haver o primeiro homem, o homem em $s i$, aquele que seria pura e absoluta realidade da liberdade como possibilidade para possibilidade.

E tal impossibilidade é posta e imposta justamente pelo salto, pela estrutura circular ou de inserção. Ou seja, quando o homem é ou há, ele sempre já é ou há (já foi!) na e como inserção, isto é, em um sentido (lógos, mundo, interesse, perspectiva). Então, de fato ou imediatamente o homem se dá sempre já constituído (decaído), feito ou per-feito por um sentido, por um mundo, por um interesse ou uma perspectiva. Aqui, agora, não vai se entrar com o tema do próprio e do impróprio, do autêntico e do inautêntico, de vida ascendente e de vida decadente, de criação e de letargia ou apatia. Mas é, seria a hora, o tempo, de uma tal discussão e formulação.

No entanto, o fato de o homem, a vida humana, dar-se ou acontecer sempre já constituída ou concretizada, e isso fundado no salto, na inserção ou no círculo (isto é, no sem fundo ou sem fundamento, no a-bysso) é a razão (!) ou o fundo ontológico da definição/determinação do homem como o animal, como o vivente político, ou seja, sempre já em uma ou desde uma pólis, um mundo ou um sentido, quer dizer, sempre já jogado num contexto ou horizonte de valores, de significações, o que habitualmente também se denomina cultura.

Tanto quanto perspectiva (interesse, horizonte, sentido, mundo, lógos) vem sobre a vida, sobrevém ao homem (possibilidade de e para possibilidade) e dele se apodera ou se apropria, o homem, então, não é, não pode ser o autor, a causa, o sujeito de tal perspectiva, ou interesse, ou sentido. Ao contrário, em prevalecendo esta antevisão segundo antecedente e conseqüente, causa e efeito, há que dizer-se que o homem, então, antes, é resultado, é efeito ou conseqüência da perspectiva, do sentido, que sempre já se deu, aconteceu ou se interpôs. Na ânsia de causa e efeito, de antecedente e conseqüente, que é sempre vontade de certeza, de controle, vem ainda a pergunta: "mas, afinal, quê ou quem é a causa, a razão, o fundamento, o autor ou responsável?" A evidência do salto, do súbito, nos livra do mal-estar destas perguntas. Pois o salto põe a graça do de graça, a graça da gratuidade ou do gratuito. É isso o a-bysso, o abissal na cara, na pele da vida. Não há, não precisa haver quê, quem. Isso, a saber, um quê ou um quem, uma causa, uma autoria, a responsabilidade de um sujeito, estragaria tudo, envenenaria tudo. Melhor, azedaria o caldo... Nada de ingratidão, de bípede ingrato!... 
Homem, Realidade, Interpretação $\mid$ Prof. Dr. Gilvan Fogel

8. Interesse, perspectiva (sempre um verbo do/no viver ou existir), define o modo de ser de vida, de existência, que se caracteriza como afeto (i.é, modo de ser que vem sobre, que sobrevém ao homem e, assim, dele se apropria, ou seja, lhe dá seu próprio, quer dizer, o próprio de ou da perspectiva) e, então, define vida, existência igualmente como inserção ou circularidade. Justamente esta estrutura é dita em e com inter-esse, quer dizer, o ser já desde dentro (inter) de um determinado modo de ser (esse), o qual, por seu lado, se define como per-spectiva, ou seja, um ver (spicere), i.é, aparecer ou mostrar-se, que se faz ou se dá desde e através (per) do elemento ou medium, no qual se está, se é inserido ou jogado. E esta estrutura decide ainda pelo modo de ser do real, de todo e qualquer real, que é ser sempre desde e como relação. A relação que se faz desde e como inserção ou circularidade, isto é, desde e como medium ou elemento. E como é, como se dá ou se faz esta relação?

É, dá-se ou faz-se tal como relação precisa ser compreendida em seu sentido próprio, mais próprio. Ou seja, medium ou elemento põe, impõe que relação seja compreendida nela mesma, desde (a partir de) ela mesma e não desde ou a partir dos pólos, dos termos ou dos relata. Expliquemos.

Normalmente, habitualmente, relação é entendida, subentendida como o óbvio da referência de um termo ou pólo (A) a outro termo ou pólo (B). É A que se refere a $\mathrm{B}$, ou B que se refere a A, ou, simultânea e dialeticamente, A referindo-se a B e B referindo-se a A. Esta estrutura, exemplificada bipolarmente, pode ser poli- ou multi-polar. O decisivo é que o ponto de partida ou a suposição é sempre o pólo, o termo - os pólos, os termos ou relata.

Este modo de compreender e subentender relação, sendo o habitual, é tardio, epigonal ou decaído. Neste sub-entendimento impera um modo de ser, a saber, o da referência bi- ou multi-polar, que encobre e escamoteia a relação propriamente dita, seu modo próprio de ser relação, à medida que sobrecarrega, mesmo isola e sedimenta, os termos consolidados, os pólos tardiamente cristalizados, cada qual como um em si e um por si. Na verdade, quando um, dois ou vários termos ou pólos aparecem, sendo um para o outro e o outro para o um, isso se dá, só pode se dar, porque relação já se deu ou já se abriu, isto é, já abriu-se ou instaurou-se a possibilidade de, p.ex., A ser para B e B ser para A. Esta possibilidade, esta abertura, é ou constitui propriamente a relação ou, se se quer, tal possibilidade é o fundo, o fundamento abissal (súbito, i-mediato, desde e como salto) ou o estrato ontológico de relação enquanto tal. Sem esta possibilidade, A jamais seria, jamais poderia ser para B e B jamais seria, poderia ser para A, de 
Homem, Realidade, Interpretação $\mid$ Prof. Dr. Gilvan Fogel

modo a se referirem mutuamente. Dito de outro modo, A pode ser para $\mathrm{B}$ e $\mathrm{B}$ pode ser para A porque, isto é, graças ao fato que o espaço (=lugar ontológico) ou o âmbito (=lugar ontológico), no qual se instauram, podem se instaurar A e B como A e B e sendo um para o outro e o outro para o um - enfim, porque tal espaço ou âmbito já se abriu, já se deu ou se instaurou. E tal âmbito ou espaço abre-se, instaura-se i-mediatamente, quer dizer, súbita ou de repentemente, e, por isso, graças a isso, não se pode, não se tem o direito de jamais tomar ou apreender os termos ou os pólos (A e B, p.ex.) antes e fora desta inserção, isto é, antes e fora da relação propriamente dita, como se fossem, como se pudessem ser isso que denominamos termos ou pólos, cada qual em si e por si. A fala de e a partir de termos ou pólos é uma vesgueada, é fala de quem está distraído, fala de quem, "acordado, está dormindo", diria Heráclito. Isso é lei de, do círculo.

Relação é, pois, o medium, o elemento (como se diz que o ar é o elemento do pássaro, a água o elemento do peixe) e isso define afeto, páthos. E, mais uma vez, esta relação, por ser afeto e assim sendo afeto ou páthos, pode e precisa ser denominada, para se fazer mais espessa e então também mais visível, inter-esse ou per-spectiva.

9. Diz-se interesse ou perspectiva uma vez que, teórico-especulativamente, ambos estão dizendo, mostrando o mesmo fenômeno, uma mesma experiência constitutiva de vida, de existência, a saber, vida ou existência (então as coisas, todas as coisas) como sendo afeto. O é, todo é, é afeto. Este é o sentido, a determinação própria de valor. Deixemos isso, valor, porém.

Mas o que se quer mostrar, destacar, é que o homem (e então também as coisas), não tem afeto(s), mas é afeto(s). Afeto faz homem vir a ser homem, assim como faz coisa, toda e qualquer, vir a ser coisa - a coisa que é e tal como é, isto é, mostrando-a, tornando-a ou fazendo-a visível. Realizando-a.

O homem não é um dentro, um interior, já dado ou constituído (um eu, uma alma, um espírito, um consciência, pessoa, etc.) e então dotado, acrescido de afetos, que vêm de fora, que aderem, que se somam ao homem e que o homem, então, por ação de sua subjetividade ou de sua vontade, projeta, aplica sobre as coisas externas, também já dadas, sub- e pré-existentes, assim colorindo-as com tais afetos, imantando-as ou modelando-as, de acordo com sua subjetividade, seu interior, seus sentimentos. Nesta visão, segundo esta compreensão, tanto homem quanto coisas pré- ou sub-existem ao afeto, que passa a ser mais um 
Homem, Realidade, Interpretação $\mid$ Prof. Dr. Gilvan Fogel

adereço, mais um valor agregado, mais um componente somado, acrescentado, seja ao homem, seja ao real, às coisas.

Mas como mostrar, como explicar que tanto homem quanto real, quanto as coisas, não existem, não sub- ou pré-existem ao afeto, i.é, que não hão e não se dão antes e fora de afeto? Como realmente entender e esclarecer, mostrar, perspectiva ou interesse em seu modo de ser arcaico-originário ou imediato?

10. "Fazer ou tornar visível" é uma expressão que tomamos emprestada de Paul Klee, em um pequeno escrito, intitulado "Confissão criadora", onde ele diz: "A arte não reproduz o visível, mas faz, mas torna visível"3. Como entender isso?

Arte - tomemos, privilegiando Klee, a pintura. Habitualmente (no mundo do pensamento, o hábito é sempre a megera, sempre "l’infamme" a "ècraser"), quer dizer, vendo a pintura não desde o artista, desde o pintor, mas justamente desde o hábito ou o senso comum, entende-se, grosso modo, mais ou menos assim: a coisa, o motivo, a ser pintada(o) está aí, à frente do pintor, dada e pronta ou acabada. O artista, o pintor, vai postar-se diante dela e ou vai copiá-la, reproduzi-la, fixando-a num decalque (isso seria o reproduzi-la natural, realista, coisista ou coisalmente), ou, então, vai pintá-la modificando- $a$, transformando- $a^{4}$ e esta modificação é entendida como a aplicação sobre a coisa, sobre o motivo, de certas técnicas ou, então, projetando sobre a coisa, sobre o motivo, os sentimentos, os valores, as intenções, as vivências, os gostos, as idiossincrasias, enfim, aplicando ou projetando todo o mundo interior, psíquico, psico-social do artista, do pintor, sobre a coisa, sobre o motivo.

No entanto, é possível entender o pintar, a pintura, de um outro modo, que pode ser uma experiência radical, i.é, essencial, fundadora de um artista, de um pintor, e que passa a ser a medida para se compreender a frase citada de Klee.

Em algum lugar, disse Cézanne que, "na pintura, a linha é a cor". Isto quer dizer: na pintura, desde a experiência da pintura (esta dimensão, horizonte ou perspectiva) a cor é a própria coisa, pois "linha", nesta citação de Cézanne,

3 Cf. Klee, P., Sobre a arte moderna e outros ensaios, Zahar, Rio, 2001, p. 43, trad. Pedro Sussekind. O original alemão diz: "Kunst giebt nicht das Sichtbare wieder, sondern macht sichtbar".

4 Não deformando- $a$, p.ex., no sentido reivindicado pelo próprio Klee e, depois, por Francis Bacon e mesmo outros, no sentido de, através desta deformação, desconstrução ou mesmo destruição, conquistar, reconquistar a gênese da coisa, sua força geradora, pela via do desfazer para ver como foi feito, e então, pintando, apontar, insinuar, mostrar, co-pintar, melhor, co-fazer tal gênese, tal força geradora. 
Homem, Realidade, Interpretação $\mid$ Prof. Dr. Gilvan Fogel

está dizendo o lugar e a hora (lugar ontológico, forma ou gênese) de coisa ser coisa; de coisa, qualquer que seja, fazer-se ou tornar-se a coisa que é e tal qual é, aparece, se mostra. Em outros termos: na pintura, como pintura, cor é princípio de realidade (arché), cor funda, isto é, instaura, inaugura real. E isso, este modo de ser, é linha. E isto quer ainda dizer: assim, desde uma tal visão ou experiência, pintura faz-se, torna-se a instância, a dimensão (perspectiva, interesse), na qual, desde ou a partir da qual o real se evidencia como sendo, como podendo e precisando ser - pintar é preciso! - a poética de cor. Poética, poiésis, está dizendo: o fazer-se, o tornar-se a ação, a atividade de gênese do real. $\mathrm{O}$ real será, em pintando, no e como pintar, o fazer-se de cor. Em uma expressão meio forçada, pode-se dizer: a coração de cor, i.é, a ação de cor fazer-se ou tornar-se cor. E, então, cor, na sua coração, faz-se o coração, quer dizer, o pulso, a cadência, o ritmo e mesmo a vida do real, de todo real possível como cor, como coração. Isso suposto que tudo pode, precisa ser pintado. A pintura, o pintar apropria-se do pintor, dele faz uso, dele até abusa e ele, então, é, torna-se, como diz ainda Klee, passagem da coisa como coisa-cor, como coisa-pintar-pintura. Como coração. Pintar é preciso, viver não é preciso.

É, portanto, desde uma tal experiência fundadora de pintura, que é preciso ler e ouvir a frase citada de Klee: a arte não reproduz, não copia, não fixa em decalque, o visível, i.é, o que é e há - isso que desde ou no senso comum, na indiferença ou apatia se mostra ou aparece como o que obviamente é, está aí; arte não reproduz o visível, mas faz, torna visível à medida que se pinta, enquanto e como a experiência, i.é, a evidência da poética de cor, da coração de cor.

A cor como poética do real, a pintura como o movimento, a dinâmica de cor se fazendo cor ( a sua coração, pois) e, assim, fazendo real, o real pintado, melhor, em pintando, fazer-se ou tornar-se real - isso é o real como o concreto da pintura, pois aí e assim, só aí e só assim o real é enquanto e como o crescer, o con-crescer de cor e real, o acontecimento cor-real. Fora de uma tal experiência, de uma tal evidência, a pintura, o pintar é abstrato, quer dizer, sem força, sem tônus, sem tempo.

Toda esta estruturação cor-pintar-real (um único e mesmo instante ou ato), Klee, em outro lugar, disse com uma expressão que, em alemão, soa estranha e insólita. A isso, a esta estruturação, chama não "Form" (forma), mas "Formung" (formação), no sentido preciso de: a ação, a atividade ou a dinâmica de forma (entendida não como fôrma ou formato, bitola, mas como gênese, como gênese ontológica ou fonte do visível, do fazer-se visível - a própria luz!) se fazendo forma (form-ação), a sua en-formação ou a sua própria essencialização, 
Homem, Realidade, Interpretação $\mid$ Prof. Dr. Gilvan Fogel

pois isso, este modo de ser fala de essência se fazendo essência, se essenciando. O en-ser de ser. "Bom é forma como movimento, como ação, bom é forma atuante... Bom é formação. Ruim é forma; forma é fim, desfecho, é morte. Formação é movimento, é ação. Formação é vida", diz Klee. ${ }^{5}$ É isso nascimento, geração gênese (vir à luz, iluminar-se) e mesmo gênese de gênese, a própria vida da vida ou o real se realizando, se fazendo real desde si mesmo, a partir de si mesmo. O "si", o "si mesmo" é, precisa ser sempre a abertura, a dimensão, a perspectiva, o interesse - lugar e hora de todo e qualquer real possível. Aqui, agora, é preciso dizer: pintando, só pintando é, há. Pintar é preciso.

11. Desde uma tal experiência (experiência é sempre iluminação, evidência), o real, a coisa, toda e qualquer coisa, não é algo que está aí já dado, feito, pronto e acabado, uma mera ocorrência, e que será pintado, ou modelado, ou decalcado, ou mesmo modificado, deformado, através da projeção sobre tais coisas de sentimentos, afetos, valores, idiossincrasias do artista, da sociedade, da comunidade, etc., etc. Não. Desde uma tal extraordinária experiência, não há coisa, não se dá coisa antes e fora de pintura, antes e fora do pintar ou do jogo de cor se fazer cor e, assim, tornar-se princípio de realidade (arché) — poética. Para coisa ser ou tornar-se coisa, para ela en-coisar-se (!), para encorpar-se como coisa, como a coisa que é, é preciso pintar, é preciso tornar-se, fazer-se cor em sua própria coração e assim o real se faz real como exposição, auto-exposição de sua própria gênese, na sua formação.

Guiado, iluminado por uma tal experiência, Guimarães Rosa, fazendo uma outra viagem, cumprindo, pois, outra experiência, a da palavra, a da poética do nomear - enfim, em hora grande, ele diz: “... o ensol do sol”. Isto é, a en-solação do sol, o ensolar-se do sol ou a essenciação do sol, quer dizer, o sol se retomando sempre e a cada passo e instante em sua gênese ou ensolação. Este é o sol verbo, não substantivo. E o mesmo Rosa, em mesma hora, dirá, ainda: “... o coqueiro coqueirando, a pedra se mesmando". Quando se vê, quando se co-faz a gênese-coqueiro ou a gênese-pedra, então, o coqueiro coqueira-se, a pedra se em-pedra ou se mesma. Sim, escrever, dizer, ver na ou desde a dimensão-palavra, a partir da abertura-dizer-nomear — isso é preciso.

Sempre desde uma tal experiência abissal, i.é, gratuita, aquela criança que

5 "Gut ist Form als Bewegung, als Tun, gut ist tätige Form...Gut ist Formung. Schlelcht ist Form; Form ist Ende, ist Tod. Formung ist Bewegung, ist Tat. Formung ist Leben”. Cf. Klee, P., Die Ordnung der Dinge, Hatje, Stuttgart, 1975, p. 94. 
Homem, Realidade, Interpretação $\mid$ Prof. Dr. Gilvan Fogel

topou com aquela pedra, com aquela pedra que já é, que já se fez mundo-abertura-perspectiva-interesse-jogo - e só por isso, graças a isso a criança viu a pedra, topou, encontrou-se com ela - pois bem, assim, a criança como que diz, lá com seus botões: "brincar, jogar, é possível e preciso", pois se assim não for, se assim não se fizer, pedra não se empedra, ela não se mesma, ou seja, não se faz, não se torna visível, não se realiza como pedra. E Drummond diz: "dizer, nomear ou fazer a poética da palavra é preciso!" Miguelangelo: “esculpir é preciso!" O construtor, o empreiteiro cisma: "construir, edificar — isso é preciso!"

Pode-se ainda perguntar: afinal, o que é, p.ex., o coqueiro?! Em si, antes, fora, de todo e qualquer interesse, perspectiva ou relação - em suma, em si é nada, coisa nenhuma. Nem coisa nenhuma pode ser! Não pode ser o que quer que seja, pois falta-lhe a condição de possibilidade absolutamente necessária para ser, a saber, ser em um, desde ou a partir de um interesse, perspectiva ou abertura, isto é, um medium, um elemento. O coqueiro pode coqueirar como coração de cor, como nomeação ou poética do nomear (ele faz-se, torna-se palavra - "no começo é o verbo"!), ou como som, ou como... Sempre como um como, como isso ou como aquilo, desde ou a partir já de isso ou aquilo. Igualmente assim a pedra pode se mesmar, se empedrar como...

12. Escreveu-se acima: "a criança diz: brincar, jogar é preciso; o poeta, Drummond diz ... Miguelangelo diz... o empreiteiro diz..." Esta formulação, livre, solta, habitual, induz a um grave erro. Vamos retificar. Segundo este modo de falar, fica parecendo que brincar, jogar, poetar, esculpir, construir ou edificar são, seriam deliberações, decisões conscientes e voluntárias ou mesmo impulsos inconscientes e involuntários de criança, de poeta, de escultor, etc. Mas, não. Não, uma vez que também criança, poeta, escultor, são feitos pelo que fazem quer dizer, também eles vêm a ser o que são enquanto e como ação ou atividade das respectivas aberturas, interesses ou perspectivas. "Que cada uno es hijo de sus obras", diz o Quixote. É preciso ouvir nesta frase um princípio de ordem ontológica, de gênese de homem, de vida humana, e não algum preceito de elevação moral.

Cabe, pois, esclarecer como horizonte (abertura, interesse, perspectiva) não faz visível somente a coisa, as coisas, mas também, igualmente, o homem, isto é, o homem-criança, o homem-poeta, o homem-escultor, construtor, pescador, jardineiro. A verdade é que o homem é sempre um homem determinadamente desde um horizonte, a partir de uma perspectiva, ou seja, de uma possibilidade de ser de vida, de um verbo no/do viver ou existir. 
Homem, Realidade, Interpretação $\mid$ Prof. Dr. Gilvan Fogel

O homem não sub-está à perspectiva, ele não pré- ou sub-existe ao interesse, assim se fazendo, como entende o bom senso e todo bom cristão, o autor, a causa, o sujeito da perspectiva, do interesse. Como?!

É que na vida, no viver ou existir, o homem - ouça-se: a realidade da liberdade como possibilidade para possibilidade - se abre $a$, para transcendência, isto é, dispõe-se ou pré-dispõe-se para aquilo(!) que o ultrapassa, que o transcende. Abre-se não. Isso, de novo, pode induzir a erro, pois fica parecendo que tal abrir-se ou dispor-se fosse obra, ação, da intenção, do propósito ou da deliberação humana, ou seja, de um homem já constituído. Seria um ato, deliberado ou não, instintivo ou não, de um eu, de uma vontade, de uma consciência, de um impulso, a espontaneidade do corpo, de sinapses, uma reação psico-física, neuro-motora ou eletro-química.

O homem - ouça-se: o modo de ser que se determina como a realidade da liberdade como possibilidade para possibilidade - este homem ou modo de ser é aberto a ou para transcendência, àquilo (!) ou para aquilo (!) que o ultra-passa ou o trans-cende. Mas como é, como se dá isso?

Tal abertura, disposição ou pré-disposição dá-se ou concretiza-se sempre em um e como um modo de ser de vida, de existência (um verbo), isto é, de novo, em uma ou como uma perspectiva (ou interesse, ou horizonte, ou mundo). E uma tal perspectiva (horizonte, mundo), em sendo sempre a concretização ou a realização possível de vida, é sempre ação, dá-se ou faz-se sempre como ação ou atividade. Por isso, uma tal abertura, disposição ou perspectiva pode/precisa também ser denominada um verbo do/no viver ou existir. E por isso, desde isso ou graças a isso o homem, enquanto determinado ou constituído, i.é, como este homem, este João pescador, aquele Pedro escritor, esta Maria escultora - enfim, assim, graças a isso e por obra disso (abertura) o homem faz-se, torna-se homem, à medida que a perspectiva, o interesse ou a abertura apropria-se, apodera-se do homem (i.é, da possibilidade para possibilidade, ou seja, do modo de ser afetável, tocável por possibilidade de ser, de vir a ser ou fazer-se, tornar-se) e o usa, o explora. E é assim que se evidencia ser o homem ação, atividade, drama, quer dizer, história ou tempo se fazendo tempo. O tempo do tempo.

É decisivo ver-se que toda esta estruturação, todo este modo de ser sobrevém ao homem, à realidade da liberdade, desde... nada. Isso é o imperativo de salto, de súbito, de círculo. Desde nada, por nada, para nada - abissalmente. Gratuito. De graça. Graças a...nada! Acolher isso, render-se a isso é gratidão. É cumprir um 
Homem, Realidade, Interpretação $\mid$ Prof. Dr. Gilvan Fogel

destino, uma necessidade, que é pura doação. Liberdade. Espontaneidade. Fartura, superabundância de nada, ninguém, nenhum. Para nada. Pura gratuidade.

13. Quando algo se dá, acontece, um sentido sempre já se interpôs, sempre já se deu ou aconteceu. Sentido (lógos) está dizendo abertura, horizonte, dimensão, perspectiva, interesse. Mundo. Sentido é isso, é assim.

E assim sendo, todo e qualquer real, tudo quanto se dá e há, é interpretação. Sempre já interpretação. Interpretação é o nome da ação, da concretização ou realização (exposição) do sentido interposto. Não que haja, que se dê sentido e que interpretação venha a ser outra coisa, algo que se soma ou se acrescente ao sentido, à abertura ou dimensão. Não. Isso é uma única e mesma coisa em diferentes momentos de realização ou concretização. A análise, a exposição compreensiva e fenomenológico-descritiva, privilegia ora um, ora outro momento, ora uma, ora outra articulação da estrutura, do todo.

O entre, o inter, de interpretação e de interposição (ou interposicionamento) não é o intermediário mediando duas coisas, não é a distância média entre duas ou mais coisas ou algos. Este entre, este inter, não é espacial, nada no domínio da extensão. Antes, o inter da interpretação, assim como do sentido interposto, diz o meio, mas meio no sentido de medium ou elemento. Elemento, isto é, aquilo (!) que, ao se ver, ao se dar conta, já se vê, já se dá conta dentro, isto é, jogado nisso, todo tomado, atravessado, perpassado por isso - enfim, afetado. É, portanto, o medium ou elemento, que, por sua vez, evidencia o modo de ser da inserção súbita. "Inserção súbita" é um pleonasmo, uma redundância, uma vez que é inserção porque (graças a) é súbito, porque (graças a) é o salto que põe e impõe círculo, circularidade e afeto.

Este medium ou elemento define igualmente tanto o inter de interesse, quanto o per, de perspectiva. Pois este inter, este elemento ou medium, em falando mundo, abertura (interesse, perspectiva), fala, primeiro, do modo de ser no interior ou dentro do qual sempre já se está, sempre já se é, ou seja, fala da necessidade da vida ou da existência interessada. E, segundo, este inter, este elemento ou medium, fala igualmente do per, isto é, do através, da perspectiva, que ilumina (abre) e assim instaura (põe, inaugura) o que quer que seja, o qual já é sempre, só pode ser sempre já atravessado, perpassado por tal medium ou elemento, uma vez que é este medium ou elemento que faz, que torna visível ou instaura o que aparece ou se instaura. O ver e o aparecer, tudo que aparece ou se faz visível, só é possível porque (graças a) já é desde e como este através, desde e como este per da perspectiva. O inter, o per, o medium ou elemento - é isso mesmo a luz, a clareira irrompida, i.é, que fez-se doação. 
Homem, Realidade, Interpretação $\mid$ Prof. Dr. Gilvan Fogel

Tudo quanto é ou há, já é, só pode já ser interpretação. É isso $a$ condição. E condição incondicionada, uma vez que gratuita, sem porquê, sem para quê. Salto — pura doação.

Tal como vimos, tanto as coisas, quaisquer que sejam, quanto o próprio homem, isto é, tanto o visto ou visualizado quanto o vedor, o sujeito que vê, ambos, são obras da abertura, da perspectiva ou do interesse. Assim por isso, também o intérprete não é nenhum sujeito, nada atrás da interpretação e do interpretado, portanto, nada sub-existente ou sub-jacente à interpretação e ao interpretado, mas algo que se faz, que se fez no próprio movimento da interpretação, melhor, do interpretar. Portanto, algo que vem a ser, se faz, se torna, à medida que se faz interpretação — à medida que se concretiza interpretar.

$\mathrm{Na}$ verdade, o interpretado, o intérprete e a própria interpretação constituem um único e mesmo movimento, uma única e mesma dinâmica. Melhor: um único e mesmo acontecimento ou ato, a saber, o interpretar. Interpretar, aqui, é entendido no sentido da ação de todo e qualquer verbo no/do existir ou viver, isto é, o fato de o viver ou existir humano ser sempre em uma ou desde uma perspectiva, em um ou desde um interesse, então, sempre em um perspectivar-se, em um interessar-se, ou seja, em um fazer-se perspectiva de perspectiva ou o fazer-se interesse de interesse.

Machado de Assis, o intérprete do real, de todo e qualquer real, a partir da poética (interesse, perspectiva, abertura) do nomear, do fazer-se palavra de palavra - este Machado não sub- ou pré-existe ao escrever, ao dizer, isto é, mostrar ou aparecer no e do escrever. Só o senso comum pode ver e entender assim. Ele não é e não há, não pode ser e haver, antes e fora do escrever. É o escrever (a abertura, a possibilidade, o verbo ou perspectiva) que faz de Machado, Machado; ou seja, do escritor, escritor. Portanto, ele, o escritor, não é o sujeito do escrever, não é o autor (causa) da obra, mas, antes, ao contrário, é ele obra, acontecimento do escrever e no escrever, à medida que ele, na possibilidade de ser tomado ou tocado pela possibilidade-escrever (este verbo do/no viver ou existir), e em assim sendo tomado ou tocado por tal possibilidade, é por ela usado, pois ela, a possibilidade, sendo vida, é usar, isto é, expor-se, realizar-se, aparecer - Memórias Póstumas de Brás Cubas se escreve através de Machado, usando Machado. É insólito, mas assim é. Ele, Machado, se faz a-propriado por este próprio, que é o escrever, por este modo de ser que, em se realizando, faz vida e real se cumprirem, aparecerem, revelarem-se no dizer, como dizer. Que cada uno es hijo de sus obras. 
Homem, Realidade, Interpretação $\mid$ Prof. Dr. Gilvan Fogel

Por isso, diz Nietzsche: não se coloca, não se pode e não se deve colocar (i.é, não se tem razão ou direito de) o intérprete atrás da interpretação, isto é, o sujeito, o homem antes (ou atrás e, por isso, é ou faz-se sujeito, subjectum) do interesse, da perspectiva, como se fosse a causa da perspectiva, do interesse e, então, da interpretação. ${ }^{6}$ Em outra anotação, lê-se: "Não se tem o direito de se perguntar: 'quem, pois, interpreta'. Mas o próprio interpretar como uma forma da vontade de poder (i.é da vida) tem existência ("hat Dasein") [não porém como um 'ser' (aqui, ser quer dizer: sujeito, substância, coisa subsistente), mas como um processo, um devir] como um afeto".?

A verdade, portanto, é que sequer se deve falar de interpretação, mas só e tão-só de interpretar. Não a perspectiva, mas o perspectivar-se; não o interesse, mas o interessar-se; não "mundo", dirá Heidegger, mas o mundar-se(!) (“das Welten der Welt"), isto é, o fazer-se ou tornar-se mundo de mundo, o expor-se ou o concretizar-se de mundo, de perspectiva, de interesse. E é neste movimento, desde esta dinâmica ou atividade de auto-exposição, que se faz a textura, a carne das coisas, ou seja, é nisso e a partir disso que faz-se ou dá-se o coisar-se(!) de coisa. Pois coisa não é coisa, mas ela se coisa...!

Só há interpretar, quer dizer, o interpretado, o intérprete e a própria interpretação são fragmentos, retalhos, restos tardios, que se constituem como coisas e entulho quando se interrompe o interpretar, o perspectivar-se, o interessar-se - o viver, o existir. O chamado interpretado, o chamado intérprete e a chamada interpretação, de fato, se dão, se fazem no ato único, que é o interpretar, tendo como espaço, como lugar e hora o homem - não o homem dado e constituído já em um interpretar, tardio, pois, mas o modo de ser privilegiado (quer dizer, que tem e é uma lei própria, um modo próprio de ser), enquanto e como a realidade da liberdade como possibilidade para possibilidade. Irrupção, salto, abissalidade. Pura gratuidade.

14. O que é o homem? O animal, o animado, o vivente dotado de razão. E esta razão entendida, sobretudo, como um poder de apreender e, então, de organizar tudo que se oferece ao homem a partir da validade e da predominação dos princípios de identidade, não contradição e razão suficiente, pois principalmente isso é a razão moderna. Pois bem, isso não satisfaz, não resolve, não responde.

6 "Em última instância, é ainda necessário colocar o intérprete atrás da interpretação?" - Cf. Nietzsche, F., Vontade de Poder, op.cit., nr.. 481 ou KGW, VIII-1, 7[60], p. 323

7 Cf. op.cit, nr. 556 ou KGW, VIII-1, 2[149], p. 138 
Homem, Realidade, Interpretação $\mid$ Prof. Dr. Gilvan Fogel

Mas entendendo-se o homem como sendo originariamente coisa nenhuma, algo nenhum, substância alguma, mas só e tão só o modo de ser caracterizado como a abertura ou a aptidão, que é possibilidade para possibilidade, assim, algo de radical, de essencial pode mudar, pode se transformar. A partir dessa compreensão/determinação evidencia-se que homem é coisa nenhuma, nada dado ou constituído previamente. Como já dissemos: nem razão, nem alma, nem espírito, nem consciência, assim como também nada que poderia ser visto como o contrário de todas estas determinações, a saber, corpo, matéria, energia, fundo bio-fisiológico, substrato neurológico, nada de orgânico ou organismo. Tudo isso, que pode ser real e útil, no entanto, é tardio, nenhum dado primário, e, por isso, chega sempre atrasado quando em questão está a responsável e grave pergunta pelo homem, pela sua real textura ontológica.

A partir da evidência, segundo a qual o homem não é coisa nenhuma, outra dimensão, outra percepção ou compreensão se abre e se impõe: o homem é, só pode ser experiência (afeto) e história. Ele, isto é, este modo de ser, é possibilidade, quer dizer, a necessidade, uma vez que é possibilidade vital ou existencial e não uma mera possibilidade lógica, que se faz contingência - o homem é a possibilidade, então a necessidade, de vir a ser no fazer, como fazer, a partir do fazer. Se faz, é. Melhor: se faz, vem a ser, torna-se. Se faz, ganha textura, carne, miolo, tutano, determinação. Faz-se, torna-se um homem, este homem.

O homem faz?! Faz para vir a ser ou se fazer?! Mas quem faz, que homem faz, se não há homem, coisa nenhuma pré-fixada, antes e atrás da ação, como sendo sua causa, seu sujeito? Mas já esclarecemos: não há, não pode haver quem interpreta, isto é, quem faz, quem age.

Mas, em dizendo que o homem se faz, vem a ser só no e desde o fazer, fica dito que o homem é ação, que ele é, se faz ou vem a ser desde e como ação, atividade - é isso mesmo história. Mas aí se impõe a pergunta pela natureza, pelo modo de ser de ação, de atividade. Como é isso? Como se dá e se faz o fazer? Heidegger, abrindo Sobre o Humanismo, no embalo desta viagem da pergunta pelo homem, indicou que, "desde há muito não se pensa a essência da ação", do fazer ("Tun"). E, continua ele, não se pensa esta essência, isto é, o modo próprio de ser de ação, à medida que só se a considera como "produção de um efeito", o qual é sempre avaliado e endossado em função de sua utilidade. ${ }^{8}$

E o que quer dizer pensar, entender a ação, a essência da ação, só como "a produção de um efeito"? É entender a ação, toda ação, como o resultado, o

8 Cf. Heidegger, M., Sobre o Humanismo, Tempo Brasileiro, Rio, 1967, trás. E.C.Leão, p. 23 
Homem, Realidade, Interpretação $\mid$ Prof. Dr. Gilvan Fogel

produto de um sujeito, isto é, de um agente, de um autor, de uma causa. Este sujeito, claro, por ser sujeito, já está dado, constituído, portanto, feito, pronto e acabado antes e fora da ação. E justamente por isso ele é causa, autor, agente. Ele é o sustentador, o portador e o dono da ação, da atividade, que é uma mera conseqüência, mero resultado, efeito ou produto dele. É esta a atitude típica e tópica do tipo (estrutura) voluntarista, do tipo da autonomia da consciência, do eu, que é $o$ sujeito, $a$ substância moderna. Ou seja, é o modo próprio de ser de toda a modernidade ocidental-européia, que põe o ativismo, o operativismo do eu, da consciência, e que, por fim, conduz à técnica contemporânea, à tecno-ciência, que é o triunfo deste operativismo causal-subjetivo. O mundo cibernético é o triunfo desta ação, deste ativismo ou operativismo do eu substância, na forma da matematização e do cálculo (i.é, por antecipação contar com, controlar e, assim, assegurar-se, auto-assegurar-se) uni-formes e uni-dimensionais.

Entender a ação como ou desde só a produção de um efeito é entender, é imaginar que toda ação precisa ter um agente, uma causa, melhor, ela precisa ser o resultado ou o efeito de uma causa (o princípio de razão suficiente impõe isso), de um sujeito, mesmo de um eu - p.ex., eu escrevo, eu pinto, eu capino, eu (ou ele) jogo(a). Presente está a suposição que todo e qualquer dar-se ou acontecer, toda e qualquer coisa, dá-se ou acontece, precisa dar-se ou acontecer segundo a estrutura: ou agente ou paciente; ou ativo ou passivo. E o ativo, o agente, é a forma primeira e exemplar da ação. O paciente, o passivo, já é derivação e modificação ou transposição do agente para o paciente sofrido, constituído. O paciente é um sujeito invertido, travestido.

Em se falando de ação e dos verbos, fala-se das vozes (modos) ativa e/ou passiva. E a ação, já se disse, ou é ativa ou é passiva. Ou o sujeito pratica ação ou ele a sofre - sempre de fora. Em qualquer que seja o caso, o sujeito, o autor, o agente, já está dado e, seja ele praticando, seja ele sofrendo a ação, ele está de tal modo dado e tão completamente dado, que tal ação não tem sobre ele, nele, nenhum eco, nenhuma repercussão e, por isso, nele nada acontece, nada se transforma. Nesta estrutura, ele, o sujeito, é incólume, impermeável à ação. Intocável, in-afetável. Só e todo autor e dono dela e, portanto, fora da ação, antes da ação e imune à própria ação. Mais uma vez, este é o modo de entender tipicamente moderno, o qual vê, estrutura, organiza, esquematiza tudo a partir do esquema sujeito versus objeto, o $\mathrm{S}$ x $\mathrm{O}$, o S é P - a relação e a proposição ou enunciado exemplares. Isto é, o homem (o eu, a consciência, a vontade) do lado de cá (feito, pronto, acabado) e (+) a coisa, o objeto, do lado de lá, fora, a ser feita, isto é, passivamente constituída, modelada, no e pelo leito de Procusto do sujeito ativo. 
Homem, Realidade, Interpretação $\mid$ Prof. Dr. Gilvan Fogel

Porém, vendo, entendendo o homem e, então, também a coisa, as coisas, todo e qualquer real possível, como ou desde abertura, quer dizer, como ou desde possibilidade e mesmo e sobretudo desde e como possibilidade de e para possibilidade - assim vendo e entendendo, a medida da ação, isto é, sua essência, não mais recai sobre o sujeito, a causa, o agente da ação, e nem tampouco sobre o constituído e modelado na forma (voz) passiva, mas o que pesa, o que decide é a inserção (círculo, circularidade) e, aí, então, o medium ou elemento.

A medida da ação, sua essência ou seu modo próprio de ser, que é sua gênese e que, portanto, está sempre a se repetir ou se retomar - a medida da ação deixa de ser o ou ativo ou passivo (ou causa ou efeito, ou agente ou paciente) para ser a voz (o modo) média(o), a voz reflexa. E "média”, aqui, está evocando medium ou elemento (i.é, inserção, círculo, salto, súbito e, então, afeto) e não a média do em cima do muro, a média no sentido, p.ex., de porção igual ou a mesma quantidade (metade) de ativo e de passivo, onde a ação poderia ser um pouco, um pouquinho ativa e um pouco, um pouquinho passiva, agradando e satisfazendo democraticamente a gregos e troianos, bem ao estilo dialético e reconciliador daquele quixotesco "nem elmo e nem bacia, mas um bacielmo"! Na verdade, isso foi só picardia de Sancho Pança. Que conste esta observação, para redimir "o bom e católico" Sancho!

A ação medial, isto é, marcada ou pontuada pelo modo de ser medium ou elemento, é, na verdade, a primeira, a arcaica ou elementar, e não uma tardia e decorrente da mescla de ou ativo ou passivo. Ativo e/ou passivo é que é o tardio, o epígono, como resultado do chórismos, como conseqüência do corte e da separação do elementar da e na inserção, do e no círculo. Já vimos que na ação medial o chamado "sujeito", o ator ou autor é o chamado "efeito", isto é, vem a ser pelo, no ou graças ao fazer. Ele, o "sujeito", se faz à medida que faz o que faz, melhor, como se viu, à medida que é usado pelo fazer que se faz. Foi assim que dissemos que Machado de Assis não é o "eu escrevo", "eu sou escritor", mas sim que Machado é uso e obra do/no escrever. O escrever, no escrever e graças ao escrever, instaura, inventa, põe, propõe e impõe o escritor.

$\mathrm{Na}$ ação medial, a qual se faz desde e como participação vital, isto é, desde e como um tomar parte no/do movimento de exposição/concretização da abertura (interesse, perspectiva, mundo), é decisivo escuta. Sim, participação vital ou escuta. Aqui, escuta, ouvir, não está falando do "sentido" ou do "órgão da audição", mas do modo de ser que melhor mostra esta participação vital. Ou seja, esta participação é um tomar parte à medida que se é aptidão, melhor, disposição e mesmo pré-disposição de acolhimento e entrega à própria dimensão ou perspectiva e à sua ação, à sua atividade de exposição/concretização. 
Homem, Realidade, Interpretação $\mid$ Prof. Dr. Gilvan Fogel

Sobretudo a este acolhimento e entrega denomina-se escuta e mesmo ausculta. Assim, escuta fala do modo de ser que é abertura à abertura e, assim, por isso, participação vital ou existencial. Enquanto modo de ser vital ou existencial, a escuta, o ouvir, mostra-se igualmente como uma obediência e um assentimento, que segue, que acompanha. Nisso há uma entrega, um abandono auscultante ou ob-bediente, que é a entrega e a boa vontade em deixar-se tocar, tomar, e, desse modo, deixar-se levar, conduzir, deixando-se usar pelo uso da dimensão, da perspectiva ou do interesse. Cresce, assim, ação, atividade. Crescer, aqui, diz agravar-se, intensificar-se, apurar-se e, então, ganhar mais evidência, mais nitidez, então, mais necessidade, fazer-se ou tornar-se mais destino. Portanto, nada quantitativo, somativo, coisa de engorda e de agigantamento.

Esta escuta, sendo obediência, entrega e seguimento, pode ainda ser caracterizada como espera - "a espera do inesperado", diz Heráclito. A espera, que "é um à toa muito ativo", disse outro especulador. E em sendo esta espera do inesperado e em se fazendo um à toa muito ativo, é ela um deixar ser e acontecer e, em assim sendo e se fazendo, faz com que o modo de ser escuta e espera (i.é, o homem e só o homem) se faça passagem. Este deixar ser é uma dimensão, um modo de ser, pois, que não é, não pode ser medido, avaliado, seja por ativo, seja por passivo. Ativo-passivo, aqui, de novo, não é não pode ser medida, critério, para decidir sobre este deixar ser. O deixar ser que faz do ser/estar à escuta passagem. A passagem do que vem a ser ou se faz visível. Mais uma vez, a formulação nos vem a partir de Klee. Em Sobre a arte moderna ${ }^{9}$, fala do artista como o tipo que, na vida, no mundo, entre as coisas, conseguiu encontrar uma certa orientação, um certo caminho e, então, usa a "metáfora da árvore". Compara esta orientação nas coisas e no mundo, obtida pelo artista, às raízes da árvore, que se lançam no escuro da Terra. Deste escuro vão elas haurindo seiva, nutrientes. Neste quadro, o artista, quer dizer, o caso típico do tipo na/da ação medial ou participativo-vital, precisa ser comparado com o tronco desta árvore, o qual deixa fluir, deixa passar livremente estas seivas, provenientes do escuro da Terra, as quais aparecem na copa, como copa, ou seja, como folhação e floração - isto é, a obra, as obras de arte. Isso, a obra, é a luz do escuro, é o escuro metamorfoseado em luz. A obra, a rigor, é o modo, o único modo como o escuro (a Terra) pode aparecer ou fazer-se visível. A obra, a ação medial, que é a obra, é o próprio brilho do escuro. Note-se: o escuro não foi iluminado de fora para dentro. Se assim fosse, ele morreria. Não. Ele, desde si, a partir de si, como escuro e no escuro, iluminou-se e tornou-se brilho como luminosidade,

9 Cf. Klee, P., Sobre a arte moderna e outros ensaios, Zahar Editor, Rio, 2001, pág. 52/3, Trad. Pedro Sussekind. 
Homem, Realidade, Interpretação $\mid$ Prof. Dr. Gilvan Fogel

como fosforescência do próprio escuro, do próprio a-bysso Terra, que se fez superfície, pele. Vida é este movimento de superficialização, de iluminação do fundo, do profundo, do abissal. Não se pergunta quem dá, por que dá. Dá-se. Faz-se. Há. É. Muito obrigado! O artista, diz Klee, "assume realmente uma posição humilde", isto é, é passagem, é deixar ser. "A beleza da copa", a obra de arte, "não lhe pertence, apenas passa através dele". ${ }^{10}$

É preciso pensar, compreender toda ação a partir deste fazer exemplar do artista, deste fazer da, na, isto é, desde a arte. Em última instância, isto é, elementarmente, a ação não pertence ao homem, isto é, ele não é o dono, o sujeito, o agente. Ela passa através dele e assim o faz; faz vir a ser o ente que ele é: homem, o modo de ser histórico no e desde o fazer. Assim, in hoc signo, é preciso pregar a porta, podar a roseira, escrever e mesmo digitar o texto, lavar a louça, esfregar o chão. Sim, aqui, assim, também moram os deuses! ...

15. Algo mais se revela. Este modo de ser, que é escuta, espera, passagem, que se dá e se faz desde e como medium ou elemento — pois bem, este modo de ser, que é o homem e só o homem, enquanto e com lugar e hora de todo real possível, enfim, isto ou este modo de ser se revela como corpo, é corpo. Súbito, salto, círculo, inserção, em sendo afeto, define e decide por corpo. De novo, o arcaico, o primeiro ou o elementar de corpo não é nada da ordem do físico, do fisiológico ou do biológico (a ciência), mas tudo isso é coisa tardia, epígona e nenhum dado primeiro ou primário, como pretendem.

Homem é corpo; vida é corpo, à medida que é experiência (afeto) e história (tempo, tempo se fazendo tempo). Portanto, experiência e história são os nomes que caracterizam, que descrevem fenomenologicamente o corpo - o corpo que o homem é. O corpo que é o sentir (aísthesis, afeto, experiência), o qual, ao mesmo tempo e como o mesmo ato ou acontecimento, é ver, isto é, perceber (nous, noein). Ou seja, todo sentir (ser tocado, tomado, afetado) já é ver, co-ver, perceber ou co-perceber o sentido (i.é, aquilo pelo que foi tocado, tomado, afetado) como isso ou como aquilo, uma vez que ninguém sente impressões sensoriais, comprimentos de ondas, estímulos nervosos, sinapses, mas no sentir, ao sentir, no mesmo ato já vê-percebe algo como algo, como este ou esse algo, como isso ou aquilo determinada e especificamente. Sim, sempre já ouve-se/ vê-se o vento, o automóvel, o pio do macuco, o ranger da motocicleta. Isso é corpo como, na hora realidade da liberdade como possibilidade para possibili-

10 Idem. 
Homem, Realidade, Interpretação $\mid$ Prof. Dr. Gilvan Fogel

dade, sentir-ver, isto é, como aísthesis-nous. Assim visto e entendido, é preciso dizer: o homem é só corpo. ${ }^{11}$ É o corpo, isto é, o ato sentir-ver, aísthesis-nous, que é sua alma, sua psiché, sua vida. É isso, este acontecimento, a saber, corpo, que o anima. Ele, o homem, é, sim, corpo e só corpo - até como os próprios deuses, no olhar de Fernando Pessoa, através de Alberto Caeiro. E quando o corpo morre, a alma já morreu há muito...!

Assim sendo, logo, ergo, uma perspectiva ou um interesse (dimensão, horizonte, abertura, mundo) configura, molda, esculpe um corpo. Um corpo possível, que se faz, que se torna, que vem a ser à medida que, em se apropriando do homem, faz com que ele faça o que faz, isto é, à medida que é feito ou se faz pelo e no seu fazer. Assim, há muitos corpos. Há inumeráveis corpos. Mas não infinitos! Pois a vida, a existência é finita. Há tantos corpos quantos os reais, as realidades possíveis - isto é, os horizontes, os interesses, as perspectivas ou os verbos do/no viver, existir. E cada qual é todo o corpo, todo o real. A vida, enquanto e como concretização/exposição de perspectiva, não se despotencializa, não se gasta e se esvai, não se cansa ou se esgota, dando-se um pouco ou um pouquinho nisso ou naquilo, como isso ou como aquilo e mais (i.é, menos, no presumível processo de despotencialização) um pouquinho como aquilo outro. Não. No que se dá e se faz como isso ou aquilo, no que aparece e se faz visível como isso ou como aquilo, como este ou como aquele real (perspectiva, interesse) possível - assim e nisso, ela, a vida e então o próprio real, dá-se sempre toda(o), integral, absoluta(o). A vida nem morre! Porque viu o começo súbito e eterno, por isso, disse e mostrou Platão que a vida, a psyché, é eterna. No limite, na finitude, como exercício pleno e satisfeito de limite ou de finitude, o homem interessado é sempre todo, absoluto, per-feito. Morre sempre cheio e per-feito. Acaba cheio, inteiro, perfeito. Seu fim é sua plenitude; seu fim e sua cumulação ou per-feição, são um só e o mesmo. No fim, como fim, na morte, nenhuma choradeira, nenhuma lamentação, nenhuma falta, deficiência ou carência — um corpo cheio, redondo, esférico, per-feito. Ri satis-feito. Satis-feito, isto é, com o sentimento, a evidência de que foi feito sempre o suficiente, pois o necessário, pois o possível. Sempre. Ri satisfeito, como um Buda gordo e desdentado! E isso sempre no pouco. Como pouco. O pouco necessário. E inútil.

16. Uma ação que é entendida só como a produção de um efeito e que só é considerada, avaliada, desde sua utilidade.

11 Cf. Nietzsche, F., Assim Falava Zaratustra, I, Dos desprezadores do corpo. 
Homem, Realidade, Interpretação $\mid$ Prof. Dr. Gilvan Fogel

Nada contra a utilidade. Nada contra o útil. Nada contra o bom ou o útil para. Nada contra o ágathon. Tal como expusemos, achamos até que o homem, o homem enquanto tal, é útil, é bom para a ação. Ela como que se serve dele para fazer-se e fazê-lo. Ele, o homem, é a terra, a boa terra, na qual cai a semente, a boa semente da ação. Terra útil, terra boa para a ação.

O que não se pode, porém, é querer instrumentalizar e finalizar tudo, como se tudo fosse para $o$ ou a serviço do bel-prazer e dos caprichos da subjetividade e do voluntarismo humanos. Para que fim? Com que finalidade?! ... Pois, em última instância, qual a utilidade da ação essencial, da ação medial? Para que serve, para que presta ou se presta isso? Para que serve, para que presta, afinal, a vida?! Já se disse: é boa para o homem tornar-se homem. Serve, presta para fazer homem. E o homem, a vida - servem para quê? Prestam para quê? Resposta: para nada! Ou seja, não há nenhum sentido para fora, para além ou para aquém seja do homem, seja da vida.

A ação, a boa ação, a medial, serve, presta para a cumulação, para a plenificação da vida, para a per-feição da existência e esta serve para ... nada! Presta para ... nada! Para que fim?! Com que, com qual finalidade?! Nada. Nenhum. Nenhuma. Absolutamente sem porquê, sem para quê. Inútil. E, no entanto, não pode não ser. Inútil e necessária - a vida, a ação, a atividade gratuita. Tal como a obra de arte e tal como tudo que é grande e nobre. Grande, isto é, radical, essencial. A obra de arte é mencionada, não para enfeitar tudo, não para decorar e estilizar ou estetizar a vida, mas porque ela mostra exemplarmente a ação inútil e necessária. Assim como escalar o Everest ou correr a Maratona.

O fato é que o homem desde que é homem, desde a irrupção abissal de sua humanidade - leia-se: de sua finitude, de seu constitutivo débito, de seu ser um precisar vir a ser desde e como ação, atividade, esforço de auto-conquista e auto-realização vitais - enfim, o homem, desde a irrupção de sua humanidade, não pode não ser ação, pois ele é essencialmente ação. A ação que perfaz seu ser histórico. O seu finito, o seu limite, o seu ser pouco, parco e pobre, o qual põe, impõe ação, atividade, esforço. Esforço para a conquista do que é, do que precisa vir a ser no e desde o fazer e fazer-se. E por quê? E para quê? Por nada. Para nada. Sem porquê. Sem para quê. Absoluta, graciosa, gloriosamente inútil. Inútil e necessário. Isso é glória! Inocente. Muito obrigado! Muito obrigado! Houvesse um fim, um sentido e estaria estragada a inocência do devir, estaria azedado o caldo-vida... 
Homem, Realidade, Interpretação $\mid$ Prof. Dr. Gilvan Fogel

17. Um modo de ser — o do homem, da vida ou da existência humana que não pode ser medido nem por objetivo e nem por subjetivo. E, porque não é subjetivo e nem objetivo, também não pode ser inter-subjetivo, pois no inter-subjetivo o outro sujeito só é sujeito à medida que é objeto para o primeiro sujeito ou para mim. O inter-subjetivo é só e tão só uma combinação ou uma síntese dialética de subjetivo/objetivo, objetivo/subjetivo. É um bacielmo.

Um modo de ser (o do homem) que, igualmente, não é, não pode ser medido nem por ativo e nem por passivo. No círculo, na inserção, em sendo desde e como salto, todas estas determinações são tardias, decadentes

Pergunta-se: nesta estrutura de círculo, de inserção, de afeto, isto é, de ser desde e como medium ou elemento - enfim, nesta estrutura, como se dá saber, como se faz conhecimento? Não é, não pode ser na bitola sujeito x objeto. Quer dizer, a tradicional teoria do conhecimento, com todos os seus possíveis contorcionismos, não resolve nada, não explica ou esclarece nada. Conhecer não pode, não tem o direito de ser representação conceitual subjetiva (subjetivo-transcendental); saber ou conhecer não pode ser representar por conceitos e, assim, construir, constituir o real como âmbito da subjetividade objetivada pré- e proposta. E, no entanto, dá-se saber, faz-se conhecer, acontece conhecimento. Como?

Mas, antes, o que é saber, conhecer? É ver a coisa, o real nele mesmo e como ele mesmo. Ver quer dizer: perceber, dar-se conta de. Portanto, saber ou conhecer é ver, perceber a coisa, o real nele mesmo e aí persistir, insistir ou a isso ater-se. Mas a coisa, o real nele mesmo - o que é? O que é, como é este nele mesmo? Coisa, real, é sempre a força, i.é, a perspectiva, o interesse (horizonte, mundo, sentido, lógos), no qual, a partir do qual o real (a coisa) é real (coisa). Portanto, ver, perceber, dar-se realmente conta de algo, de um possível real, é ver, co-ver a sua força, a sua perspectiva ou o seu interesse, i.é, a sua gênese, a qual se constitui no próprio da própria coisa, do próprio real. Ver, perceber a coisa nela mesma, o real nele mesmo é ver, é perceber a coisa ou o real em sua própria força ou gênese, isto é, desde ou a partir de sua própria força ou gênese. A força, a gênese (a perspectiva, o interesse, o sentido ou o lógos) é o próprio da coisa, é o ele mesmo nele mesmo do real. Saber, conhecer, é, pois, sintonizar-se, sincronizar-se com o fazer-se coisa de coisa, com a própria realização do real. Neste sentido, saber, conhecer, é um autêntico co-nascer. Entrar na, participar da própria gênese - isto é, de algum modo, ser a própria gênese de gênese. Recordando Klee, co-ser e co-fazer forma, isto é, ser formação, "Formung".

Foi dito: de algum modo ser a própria gênese e, assim, tornar-se gênese de gênese. Mas que modo é este? Ou seja, como realmente ver, co-ver gênese, e 
Homem, Realidade, Interpretação $\mid$ Prof. Dr. Gilvan Fogel

assim autenticamente participar, tomar parte em? Como se dá, realmente, saber e conhecer enquanto e como participação vital, enquanto e como consangüinidade com a própria coisa, com o próprio real? E foi dito também: entrar na própria gênese, no próprio real. Então se está ou se estava fora? Fora, tal como o sujeito está fora da coisa (do mundo) e, então, faz-se necessária a justificação da passagem, da ponte? Estamos na mesma aporia da teoria do conhecimento?!

18. Não se trata de estar fora, pois, aqui, o absoluto é a vida e do absoluto ou em relação ao absoluto nunca se está, jamais se pode estar fora. A forma, a estrutura é de inserção, de círculo. A esta estrutura, aqui, se chama absoluto. Assim, pois, não se trata de estar fora, mas, antes, de conquistar a ou uma dimensão possível (perspectiva, interesse, sentido, mundo, abertura ou modo possível de ser), na qual já se está, quer dizer, a qual já se é, pois se vive, se está jogado na vida, no viver ou existir. Há, sim, que tornar-se, vir a ser o que é, ou seja, a possibilidade que se é - Vem a ser o que tués.

À medida que o homem é homem, à medida que vive, ele, em princípio, é (tem) todos os modos possíveis de ser de vida, todos os seus verbos (dimensões, perspectivas, aberturas, mundos), uma vez que, em vivendo e porque vive, ele é ou está na possibilidade de um tal ou tal modo de ser. E ele virá a ser ou tornar-se-á um tal modo de ser à medida que ele o conquistar. E como conquistar? Como e por que conquistar o que já se é, isso em que já se está?! E tal conquista - será ela um ato heróico, algo voluntarista, decisionista? Alguma aventura napoleônica?

Não. Conquistar, aqui, quer dizer: tornar-se tal modo de ser. Melhor ainda: tornar possível tornar-se tal modo possível de ser. E alguém se torna tal ou tal modo possível de ser à medida que se o faz, que se o realiza, i.é, que se participa ou se toma parte no seu modo de fazer-se ou de realizar-se, ou seja, de ex-pôr-se. Portanto, conquista-se um tal ou tal modo de ser à medida que se cumpre e, assim, se participa de um tal ou tal modo possível de ser, o qual se apresenta ou se expõe como um sentido, uma abertura, dimensão - mundo, interesse, perspectiva.

No entanto, a pergunta permanece: como cumprir, como participar, como tornar-se uma tal ou tal possibilidade, um tal ou tal modo possível de ser? Isso acontece ou é possível à medida que nos transpomos para uma tal ou tal possibilidade ou dimensão. E transpor-se quer dizer: pôr-se, colocar-se na e, assim, desde a própria dimensão, abertura ou interesse. Isso será participação ou con- 
Homem, Realidade, Interpretação $\mid$ Prof. Dr. Gilvan Fogel

sangüinidade com o modo próprio de ser, com a dimensão ou abertura. E esta transposição, por sua vez, se faz, se dá através de salto, só desde e como salto. Passa-se, transpõe-se-se para uma tal ou tal dimensão ou abertura à medida que se salta - à medida que se salta para dentro de uma possibilidade própria de vida e que, por isso, já se é, na qual já se está, pois do contrário seria impossível o salto, a transposição. E, sim, a passagem, o caminho é o salto. O método é o salto. Só o salto.

E salto, por ser salto, é súbito, é i-mediato, quer dizer, sem nenhuma mediação ou intermediação. No entanto, há, sim, uma preparação. Como?! Então não é salto, não é súbito, imediato, inesperado?!

Tal preparação se faz desde ou a partir de algo que, com boa vontade, pode-se chamar boa vontade! Isto é, como uma disposição ou pré-disposição de passar para, de acolher a, de assentir em tal outra abertura, tal outra possível dimensão (interesse, mundo, sentido, modo de ser). Esta boa vontade, esta pré-disposição por acolher e assentir se dá e se faz desde e como espera - "Se não se espera o inesperado, ele jamais se dará, acontecerá". Espera e escuta. Melhor: espera como escuta, uma vez que espera é, precisa ser escuta, para que ela seja "um à toa muito ativo"... O salto é doação, um acontecimento de abrir-se, dar-se ou doar-se, mas o fato é que sem esta preparação, sem esta boa vontade na/da espera-escuta, enfim, sem uma tal pré-disposição tal passagem, transposição ou salto não se dará, não se fará.

Espera e escuta. $\mathrm{Na}$ espera e na escuta, na espera como escuta a entrega à transcendência. $\mathrm{O}$ abandono, o deixar ser de transcendência (a abertura que se dá, que acontece, se oferece ou se abre a...) na sua sobreveniência, no seu vir sobre ou sobrevir, e assim tomar, tocar, afetar, isto é, pegar o ente que é só e tão só a possibilidade de ser tocado e tomado, pegado (portanto, nenhum ente), à medida que é coisa nenhuma, ente algum, mas só e tão só "a realidade da liberdade como possibilidade para possibilidade". Para isso, para tal, o meio, o medium ou o elemento, além da boa vontade, é silêncio. A entrega, a espera e a escuta - tudo isso é silêncio. Silêncio e solidão. E nisso, assim, nenhum encapsulamento, nenhum intimismo ou solipsismo, mas abertura à transcendência, disposição ou pré-disposição por transcendência.

Tal salto, tal transposição, acontece quando se faz o exercício do mandamento do destino, isto é, o exercício do mandamento do envio do homem para o homem e isso por nada, para nada. E este mandamento fala, soa assim: "Deves fortalecer-te na solidão, disse o destino". ${ }^{12}$

12 Cf. Klee, P., Die Ordnung der Dinge, Hatje Stuttgart, Stuttgart, 1975, p. 78. "Erstarken sollst Du in Einsamkeit, sprach das Schicksal". 
Kierkegaard, S. O Conceito de Angustia.

Klee, P. Die Ordnung der Dinge. Stuttgart, Hatje, 1975, p. 94.

Klee, P. Sobre a arte moderna e outros ensaios, trad. Pedro

Sussekind. Rio de Janeiro, Zahar, 2001.

Heidegger, M. Sobre o Humanismo, trad. E. C. Leão. Rio, Tempo Brasileiro, 1967.

Nietzsche, F. A Vontade de Poder, Rio de Janeiro, Contraponto, 2008, ou KGW VIII-1.

Nietzsche, F. Assim Falava Zaratustra.

Copilação bibliográfica feita pelos editores, a partir das referências indicadas em notas no corpo do texto 